\title{
Video-assisted multivessel revascularization through a left anterior small thoracotomy approach with the Symmetry Aortic Connector System
}

\author{
Michal Semrád, MD, PhD \\ Petr Bodlák, MDa \\ Martin Stříteský, MD, $\mathrm{PhD}^{\mathrm{a}}$ \\ Vladimír Vondráček, $\mathrm{MD}, \mathrm{PhD}^{\mathrm{a}}$ \\ Tomáš Urban, MDa \\ Petra Vyhnalová, MDa \\ František Holm, MD, PhD ${ }^{b}$ \\ Ivan Vaněk, MD, $\mathrm{PhD}^{\mathrm{a}}$
}

See related editorial on page 27.
From the Department of Cardiovascular Surgery $^{\mathrm{a}}$ and Internal Department, ${ }^{\mathrm{b}}$ Charles University Teaching Hospital, First Medical Faculty, Prague, Czech Republic.

Received for publication April 11, 2002; revisions requested June 14, 2002; revisions received June 29, 2002; accepted for publication July 2, 2002.

Address for reprints: Michal Semrád, MD, $\mathrm{PhD}$, Department of Cardiovascular Surgery, Charles University Teaching Hospital, First Medical Faculty, U nemocnice 2, 12800, Prague 2, Czech Republic (E-mail: semradm@volny.cz).

J Thorac Cardiovasc Surg 2003;125:129-34

Copyright $(\odot 2003$ by The American Association for Thoracic Surgery

$0022-5223 / 2003 \$ 30.00+0$

doi: $10.1067 / \mathrm{mtc} .2003 .79$
Objective: We sought to demonstrate the applicability of video-assisted multivessel revascularization through a left anterior small thoracotomy approach with the use of the Symmetry Aortic Connector System (St Jude Medical Anastomotic Technology Group, Inc, St Paul, Minn) as an alternative to the standard median sternotomy approach and to evaluate predischarge angiographically documented graft patency.

Methods: From October 2001 through February 2002, a total of 15 patients with triple-vessel disease were operated on through a left anterior small thoracotomy approach with video-assisted port-access construction of proximal aorta-to-saphenous vein anastomoses with the Symmetry Aortic Connector System and cardiopulmonary bypass with femoral cannulation and without cardioplegic arrest. There were 9 male and 6 female subjects with a mean age of $68.3 \pm 3.6$ years and an average ejection fraction of $55.8 \% \pm 19.6 \%$. Subject inclusion criteria consisted of female sex (initially but not throughout the study), coronary artery reoperations, and sternal bone disease. Subject exclusion criteria consisted of an age younger than 65 years, extensive atheromatous plaques in the ascending aorta, and aortoiliac occlusive disease. All but 1 patient underwent angiographic patency evaluation before discharge.

Results: Fifteen operations were performed successfully without any deaths. Twenty-nine sutureless proximal anastomoses were performed, with an average of $3.13 \pm$ 0.62 distal anastomoses per patient. Eleven (73\%) patients underwent a fast track protocol with extubation in the operating room. We did not observe any instances of low cardiac output syndrome, stroke, renal insufficiency, wound complication, or perioperative myocardial infarction. A single episode of atrial fibrillation occurred in this group. Angiographic assessment of 44 bypass grafts and target arteries was performed, and $86 \%$ of those examined were widely patent (FitzGibbon score A).

Conclusions: We have demonstrated a potential advantage of the sutureless Symmetry Aortic Connector System as a suitable approach that affords minimal access. Video-assisted multivessel revascularization through a left anterior small thoracotomy approach with an automated mechanical anastomosis device is particularly useful in patients undergoing coronary artery bypass reoperations or those at risk of poor sternal healing or infection. This approach seems to be a safe alternative to standard median sternotomy. 


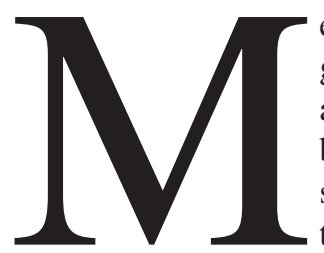

edian sternotomy is the standard surgical approach for most cardiac operations. However, limited incisions are being increasingly used in less invasive coronary artery revascularizations such as minimally invasive direct coronary artery bypass (MIDCAB), lateral MIDCAB, and the subxiphoid approach. ${ }^{1,2}$ Additionally, there is a group of patients for which a different approach may be beneficial, particularly those undergoing coronary artery bypass reoperations and those with sternal bone pathologic conditions. ${ }^{3,4}$ The cosmetic advantage of a small incision is also worth noting. Video-assisted port-access proximal venous graft anastomosis with a mechanical device and onpump technique allows the use of a left anterior small thoracotomy (LAST) approach in the aforementioned group of patients.

\section{Methods}

\section{Patients}

From October 2001 through February 2002, a total of 15 patients with triple-vessel disease were operated on through a LAST approach with video-assisted port-access construction of proximal aorta-to-saphenous vein anastomoses with the Symmetry Aortic Connector System (St Jude Medical Anastomotic Technology Group, Inc, St Paul, Minn) and cardiopulmonary bypass with femoral cannulation and without cardioplegic arrest. The group consisted of 9 male and 6 female patients with a mean age of $68.3 \pm 3.6$ years and an average ejection fraction of $55.8 \% \pm$ $19.6 \%$. Seven cases were reoperations, 2 patients had multiple myeloma with fragile and cavernous sternal bones, and all 6 female patients insisted on a small submammary incision. Female gender was an inclusion criterion in the beginning of our study because of the cosmetic benefits of this rather expensive method. The aims were to test the accessibility of the ascending aorta and target arteries and to assess the condition of all anastomoses. Subject exclusion criteria included an age younger than 65 years, extensive atheromatous plaques in the ascending aorta, aortoiliac occlusive disease, and the presence of single- or double-vessel disease suitable for the off-pump LAST approach. The institutional ethics committee approved this study, and informed consent was obtained in all cases. One surgeon performed all the operations. Preoperative variables are summarized in Table 1. Angiographic evaluation of graft patency was performed before discharge in 14 cases. Informed consent for cardiac catheterization was given by all but 1 patient. Each bypass graft was classified according to the FitzGibbon scale..$^{5}$ All graft lesions were scored according to their worst angiographic appearance in all views. Each graft was evaluated over its entire length, including proximal and distal anastomoses.

\section{Surgical Technique}

When the decision to perform a complete revascularization through the LAST approach was made, aortoiliac and femoral arteries were examined with duplex ultrasonography, followed by transesophageal echocardiographic visualization of the ascending
TABLE 1. Demographic and preoperative clinical data $(\mathbf{n}=$ 15)

\begin{tabular}{lc}
\hline Mean age (y, mean \pm SD and range) & $68.3 \pm 3.6(67-81)$ \\
Mean ejection fraction (mean \pm SD & $55.8 \% \pm 19.6 \%(19 \%-68 \%)$ \\
$\quad$ and range) & $4(27 \%)$ \\
Ejection fraction $<35 \%$ (No.) & $6(40 \%)$ \\
Female (No.) & $4(27 \%)$ \\
Diabetes (No.) & $3(20 \%)$ \\
Chronic obstructive pulmonary & \\
$\quad$ disease (No.) & $7(47 \%)$ \\
Previous coronary artery bypass & \\
$\quad$ grafting (No.) & $8(53 \%)$ \\
Previous myocardial infarction (No.) & $2(13 \%)$ \\
Multiple myeloma (No.) & $2(13 \%)$ \\
Left main coronary artery stenosis & \\
$\quad$ (No.) & $1(6.6 \%)$ \\
Emergency cases (No.) &
\end{tabular}

aorta, before an incision being made. Patients were prepared as for conventional cardiac surgery. Combined thoracic epidural anesthesia was induced with a single-lumen endotracheal tube that was endoscopically advanced into the right main stem bronchus before left internal thoracic artery (ITA) dissection. After intubation, patients were placed in a modified right lateral decubitus position. The greater saphenous veins were harvested endoscopically (Clearglide Endoscopic Vessel Harvesting System; CardioVations, Ethicon Inc, Somerville, NJ) or with the open technique, and the right femoral artery and vein were exposed. Venous graft segments were loaded into the Symmetry Aortic Connector System.

A small 8-cm left anterior thoracotomy was performed along the fifth intercostal space without rib resection. A pediatric rib retractor was placed into the incision, and when possible the left ITA was mobilized and prepared for grafting with a rib elevator Access MP Lift Set (Giudant Corp, Indianapolis, Ind). After heparin administration, the femoral artery and vein were cannulated with a long venous cannula from the femoral vein to the right atrium. Cardiopulmonary bypass was instituted without patient cooling. We did not achieve an empty beating heart for target arteries stabilization and distal anastomoses performance in our first case. Further decompression of the right side of the heart was achieved by immediately connecting a negative pressure line to the blood reservoir. This was found to be more straightforward than vent insertion into the pulmonary artery or left ventricle through this approach. A vacuum-assisted venous return was effective in yielding adequate heart decompression without the need for additional heart venting in the remaining cases. ${ }^{6}$

The pericardium was opened longitudinally from the apex to the ascending aorta, and in reoperations lysis of adhesions was completed with bipolar scissors (Powerstar; Ethicon Inc, Somerville, NJ). Patent ITA isolation seemed to be more straightforward through a left thoracotomy. The ascending aorta was visualized with pericardial traction stitches and a rigid $30^{\circ}$ endoscope (Olympus A 5195A/OTV-S6; Olympus Optical Co, Ltd, Tokyo, Japan). An appropriate site for the proximal venous graft anastomoses was selected. The following steps were found to be essential. Because it was necessary to insert an aortic connector at a $90^{\circ}$ angle, a suitable region on the left (Figure 1) or right (Figure 2) lateral 


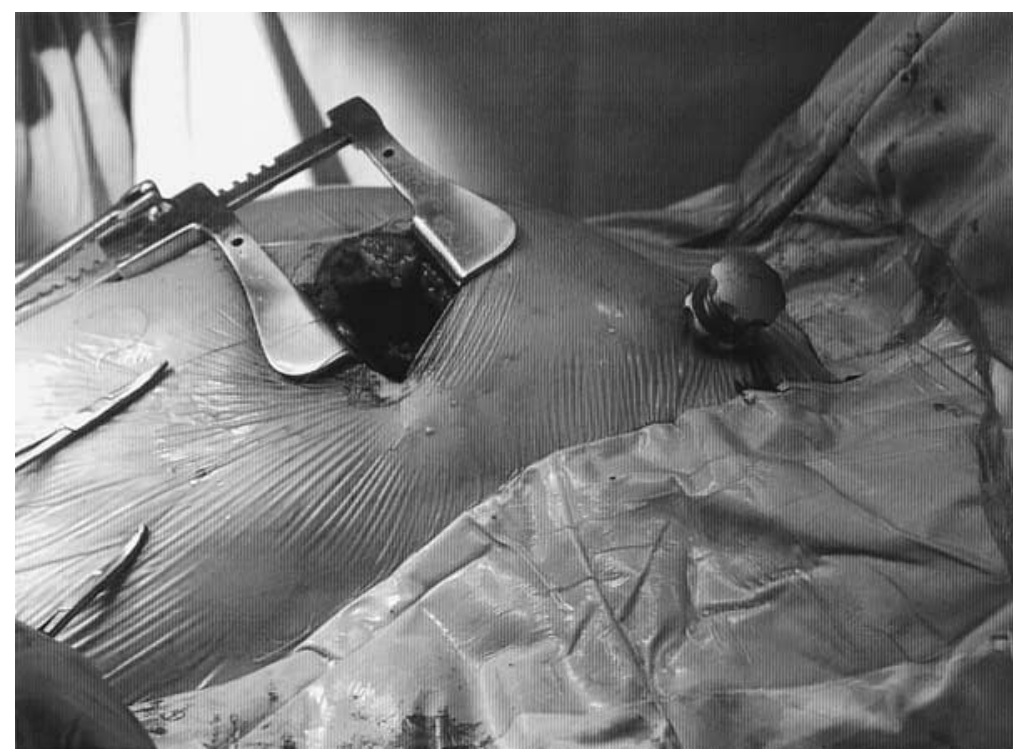

Figure 1. Port-access venous graft central anastomosis from left side (ie, obtuse marginal, left anterior descending coronary artery) through the second intercostal space and left anterior axillary line.

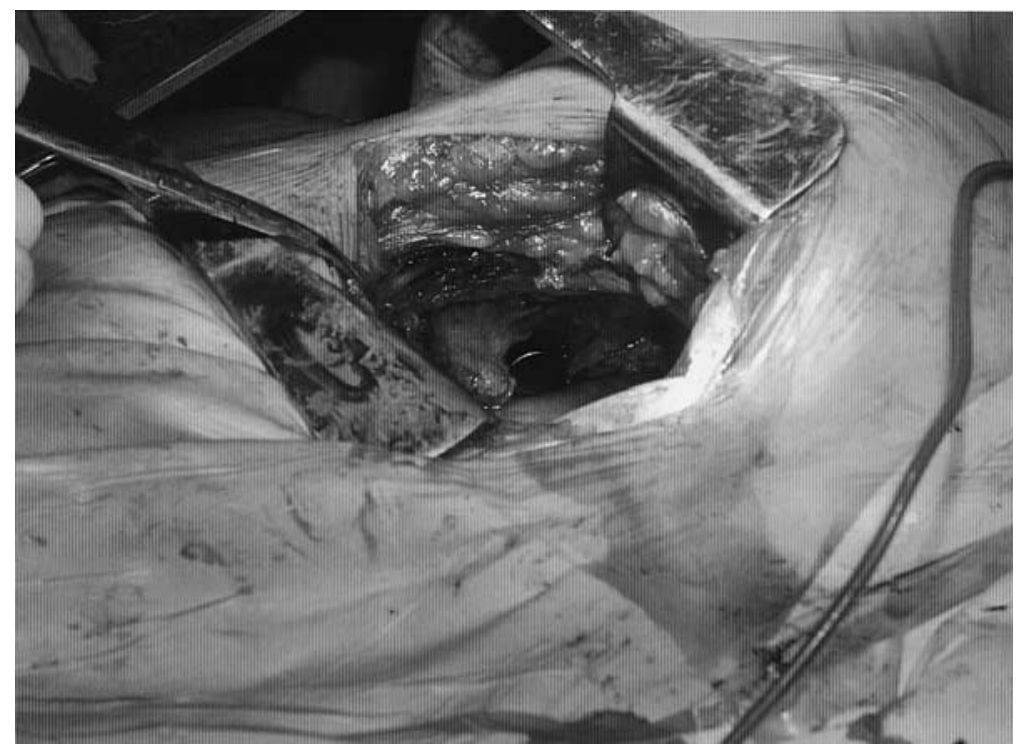

Figure 2. Port-access venous graft central anastomosis from right side (right coronary artery) through third intercostal space and right parasternal line. The port is just above ascending aorta, view from LAST.

chest wall needed to be found. This could only be performed accurately by means of video assistance. Once an appropriate area was found, a small skin incision was performed and a 12-mm metal Olympus port was passed through the intercostal space into the pleural cavity.

Occasionally, left-sided central anastomoses on the ascending aorta were reached through a LAST incision without the need for port insertion because of the fortunate anatomic conditions of the elongated aortas. Passing any straight and narrow instrument through the ports or LAST incision toward the ascending aorta permitted us to confirm the correct $90^{\circ}$-angle positioning. The camera was positioned, and the aortic cutter was passed through the port to the target area. This was followed by passage of the loaded delivery device. For a brief period, from the time that the aortic cutter was removed until the moment that the delivery system was positioned, bleeding was controlled with a small tampon on the tip of a hemostat. Grafts were deployed, properly measured, and shortened to reach the distal anastomoses without kinking. There were no body habitus or skin-to-aorta distance limitations observed with port-access in the venous grafts deployed. 
TABLE 2. Early postoperative outcomes $(n=15)$

\begin{tabular}{lc}
\hline Distal anastomoses & 47 \\
Distal anastomoses/patient (mean \pm SD) & $3.13 \pm 0.62$ \\
Sutureless proximal anastomoses (No.) & 29 \\
Left anterior descending, diagonal & $15(32 \%)$ \\
$\quad$ targets (No.) & $17(36 \%)$ \\
Obtuse marginal targets (No.) & $15(32 \%)$ \\
Right coronary artery, posterior & \\
$\quad$ descending artery targets (No.) & $12(80 \%)$ \\
Left ITA used (No.) & $7(47 \%)$ \\
Endoscopic vein harvesting (No.) & $112 \pm 34$ \\
Mean cardiopulmonary bypass time & \\
$\quad$ (min, mean \pm SD) & $186 \pm 52$ \\
Mean procedural time (min, mean \pm & \\
SD) & $11(73 \%)$ \\
Fast track (No.) & $1(6.7 \%)$ \\
Respiratory disorders (No.) & $1(6.7 \%)$ \\
Atrial fibrillation (No.) & $425 \pm 175$ \\
Blood loss (mL/24 h, mean \pm SD) & $0(0 \%)$ \\
Reexploration for bleeding (No.) & \\
Blood transfusion (transfusion units) & 10 \\
Overall & 0.7 \\
Per patient & $8.6 \pm 4.4$ \\
Intensive care unit time (h, mean \pm SD) & $5.54 \pm 1.12$ \\
Hospital stay (d, mean \pm SD) & $0(0 \%)$ \\
Death (No.) & $3.1 \%$ \\
Predicted mortality & \\
\hline
\end{tabular}

We were able to reach all target lesions in every coronary artery without crossclamping or cardioplegic arrest by using a standard vacuum stabilizing device (Octopus II; Medtronic, Minneapolis, Minn) mounted on the arm of the pediatric rib retractor. We did not insert any loops or stay sutures around the coronary arteries but routinely used intraluminal shunts. Distal anastomoses were performed with running 7-0 or 8-0 Prolene sutures (Ethicon). Heparin was reversed with protamine. Finally, the left-side trocar incision was used for insertion of the chest tube and the left anterior thoracotomy was closed. Postoperative pain control was achieved with epidural analgesia, and aspirin was continued indefinitely.

\section{Results}

Seventeen patients were initially selected for this procedure. One patient was subjected to a standard midsternotomy approach before a LAST incision because of a heavily calcified ascending aorta on transesophageal echocardiography. Another patient did not undergo the procedure because aortoiliac occlusive disease was discovered 1 day before scheduled surgery. Only these 2 patients were excluded. Fifteen operations were successfully performed, with no deaths. In 3 patients a left ITA was not harvested because the occluded graft had been used in a previous operation. A patent left ITA with stenosis at the anastomotic site was successfully freed from adhesions in another operation, reanastomosed, and three additional venous grafts were constructed. The number of distal anastomoses per patient averaged 3.13 and ranged from 2 to 4 . Twenty-nine sutureless proximal anastomoses were performed, 23 for
TABLE 3. In-hospital evaluation of graft patency $(n=14)$

\begin{tabular}{lcr}
\hline & No. & $\%$ \\
\hline Distal anastomoses & & \\
$\quad$ Per patient & 3.14 & \\
Total & 44 & 100 \\
Patent distal anastomoses (FG A and B) & 42 & 95 \\
Intact grafts and anastomoses (FG A) & 38 & 86 \\
Arterial graft anastomoses & 11 & 100 \\
$\quad$ Total & 0 & 0 \\
Arterial conduit occlusions (FG 0) & 1 & 9 \\
Arterial conduit stenoses (FG B) & & \\
Venous graft anastomoses & 33 & 100 \\
$\quad$ Total & 2 & 6 \\
Venous graft occlusions (FG 0) & 3 & 9 \\
$\quad$ Venous graft stenosis (FG B) & 1 & 7 \\
Patients with percutaneous transluminal coronary & & \\
angioplasty for graft stenosis & &
\end{tabular}

FG, FitzGibbon score.

single venous grafts and 6 for sequential venous grafts. This anastomotic device did not allow $\mathrm{Y}$ venous graft loading; however, a hand-sewn vein-to-vein proximal anastomosis could still be performed based on a venous graft in which the connector system was previously used. We did not observe any cases of low cardiac output syndrome, stroke, renal insufficiency, wound complication, or perioperative myocardial infarction. The early postoperative outcomes are summarized in Table 2.

Surprisingly, only 1 episode of atrial fibrillation occurred in this group. Postoperative pain did not differ from that observed with MIDCAB procedures. Angiographic follow-up confirmed that arterial conduits $(0 \%$ FitzGibbon score $\mathrm{O}$ ) were superior to venous grafts, but we did not find an unexpected number of saphenous venous graft occlusions (6\% FitzGibbon score O) or stenoses (9\% FitzGibbon score B). We recorded 6 (13.6\%) FitzGibbon O and B lesions in 44 bypassed arteries in our small group, predominantly in the bodies of the saphenous venous grafts. Assessment of 2 lesions in 3 grafts of 1 patient led to percutaneous transluminal coronary angioplasty early in our series (Table 3). We did not observe any stenoses in sutureless proximal anastomoses or any sharp angulations immediately below them. However, we found kinking in the mid or distal portion without stenosis in 3 venous grafts.

\section{Discussion}

An approach to effect complete myocardial revascularization through a small thoracotomy for multivessel coronary artery disease, the Dresden procedure, has been described. This procedure is performed on pump with a certain amount of ascending aortic manipulation. ${ }^{7,8}$ Alternative approaches include the off-pump Srivastava procedure through a large left thoracotomy (presented at the Seventh Annual Cardiothoracic Techniques and Technologies [CTT] Meeting in 
2001) and Watanabe's off-pump mini-invasive approach with arterial grafts, but only with target areas on the left anterior descending-obtuse marginal systems. ${ }^{9}$

As surgeons become more comfortable with beatingheart surgery and improved stabilization devices are becoming available, coronary artery bypass grafting through the left side of the chest on the beating heart presents itself as a straightforward procedure. We have presented here a videoassisted method that facilitated port-access central anastomosis on the ascending aorta with the Symmetry Aortic Connector System. This technique was successfully used on a patient undergoing urgent minimally invasive direct coronary artery bypass in which the left ITA was not harvested because of subtotal occlusion of the left subclavian artery. In this study, we wanted to demonstrate the applicability and potential advantage of the sutureless aortic connector system to port-access construction of multiple proximal anastomoses and to recommend this procedure for selected groups of patients (those undergoing coronary artery reoperations and those with sternal bone pathologic conditions). Our first patient was an elderly woman in whom three bypasses were performed and the greater saphenous vein was harvested endoscopically. Because the cosmetic effect was remarkable, other female patients asked for this type of operation. The only logical argument for including female gender in our selection criteria for this study rested on the cosmetic effect, and of course it helped us to gain experience and training.

No difference in accessibility of the ascending aorta was found between sternotomy and the on-pump port-access approach accompanied by lung deflation. Aortic wall preoperative assessment, together with proper graft deployment, precluded any anastomotic leakage. Safe graft deployment was achieved with the ascending aorta under pressure. For this reason, the on-pump beating-heart method was used without aortic crossclamping or endoclamping and cardioplegic arrest. When a venous return cannula was inserted through the femoral vein, the heart was never completely in an empty beating state and always produced pressure waveforms. Additional heart decompression was needed only in cases of distal anastomoses. A sharp angulation immediately distal to the proximal anastomosis should be avoided in left-sided grafts by placing them to the left lateral aortic wall aspect and in right-sided grafts by placing them close to the sinotubular junction and to the anterior aortic wall aspect. A connector device enabling graft deployment in various angles would solve this problem. A smaller, flexible port and narrower twisting arm of the aortic cutter would improve the deployment of endoscopic grafts. This device provides a means for avoiding aortic manipulation, but it is not appropriate for radial arteries. Another shortcoming of this approach relative to standard sternotomy is the time-consuming video-assisted right thoracic artery dissection. The time factor was why an age limit was imposed in our group. Younger patients should be candidates for full-arterial revascularization. Age greater than 65 years is a relative contraindication, depending on institutional indication policy. We have found only two major contraindications for this procedure: calcified ascending aorta, which precludes safe graft deployment, and aortoiliac (femoral) artery occlusive disease, which prohibits cardiopulmonary bypass arterial line insertion from the groin. Large hearts with left ventricular dysfunction or deep intramyocardial coronary arteries were not a contraindication, as is the case for the off-pump cardiopulmonary bypass procedure. The surgical approach for each patient should be customized to meet the needs and wishes of that patient. The resultant esthetic benefits of a submammary incision, a small groin incision, and endoscopic vein harvesting should be considered in elective coronary artery bypass surgery in female patients. The advantages of the thoracotomy approach are most evident when considering the hazards of a reoperative sternotomy. ${ }^{10,11}$ Sternal healing is compromised in patients with surrounding tissue contamination ${ }^{12}$ (eg, tracheostomies), sternal bone pathologic conditions, or malignant disease ${ }^{13,14}$ (such as multiple myeloma in our series). A thoracotomy approach may be beneficial in avoiding sternal dehiscence and mediastinitis.

The Symmetry Aortic Connector System can be used with minimal access. Video-assisted multivessel revascularization through a LAST approach with an automated mechanical anastomosis device may be particularly useful in patients undergoing coronary artery bypass reoperations or in patients at risk for poor sternal healing or infection. The technical aspects of this approach and the potential benefits in patients at risk have been demonstrated. These include reductions in postoperative complication incidence and length of hospital stay, although our patient group was too small to support this conclusion with absolute certainty. The advantages outlined in this report and the cost-effectiveness need to be evaluated in a comparison with standard methodologies. Nevertheless, port-access with mechanical anastomotic devices represents a form of less invasive coronary surgery. When a left ITA cannot be harvested or is damaged in a MIDCAB procedure, video-assisted port-access proximal anastomosis with the Symmetry aortic connector may be an alternative to the subclavian-axillary artery to coronary artery bypass procedure and may reduce the time needed for a lateral MIDCAB to the circumflex system. Investigation of these areas remains ongoing in our group.

\section{References}

1. Subramanian VA, Patel NU. Current status of MIDCAB procedure. Curr Opin Cardiol. 2001;16:268-70.

2. Stamou SC, Bafi AS, Boyce SW, Pfister AJ, Dullum MK, Hill PC, et al. Coronary revascularization of the circumflex system: different 
approaches and long term outcome. Ann Thorac Surg 2000;70:1371-7.

3. Kawata T, Kameda Y, Taniguchi S. Modification of repeat coronary bypass grafting for the left anterior descending artery with a minimally invasive direct coronary artery bypass technique. J Card Surg. 1999; 14:366-9.

4. Subramanian VA. Clinical experience with minimally invasive reoperative coronary bypass surgery. Eur J Cardiothorac Surg. 1996;10: 1058-625.

5. FitzGibbon GM, Leach AJ, Keon WJ, Burton JR, Kafka HP. Coronary bypass graft fate: angiographic study of 1,179 vein grafts early, one year, and five years after operation. J Thorac Cardiovasc Surg. 1986; 91:773-8.

6. Mueller XM, Tevaearai HT, Horisberger J, Augstburger M, Burki M, von Segesser LK. Vacuum assisted venous drainage does not increase trauma to blood cells. ASAIO J. 2001;47:651-4.

7. Kappert U, Cichon R, Gulielmos V, Schneider J, Schramm I, Nicolai $\mathrm{J}$, et al. Robotic-enhanced Dresden technique for minimally invasive bilateral internal mammary artery grafting. Heart Surg Forum. 2000; 3:319-21.

8. Gulielmos V, Brandt M, Knaut M, Cichon R, Wagner FM, Kappert U, et al. The Dresden approach for complete multivessel revascularization. Ann Thorac Surg. 1999;68:1502-5.

9. Watanabe G, Misaki T, Kotoh K, Kawakami K, Yamashita A, Ueyama K. Multiple minimally invasive direct coronary artery bypass grafting for the complete revascularization of the left ventricle. Ann Thorac Surg. 1999;68:131-6.

10. Uppal R, Mills NL, Wechester AS, Smith PK. 1985: left thoracotomy for reoperative coronary artery bypass procedures. 1993 update. Ann Thorac Surg. 1993;55:1275-6.

11. Randolph Bolton JW. Left thoracotomy for reoperative revascularization of the posterior coronary circulation. J Cardiovasc Surg (Torino). 1997;38:407-10.

12. Nataf P, Regan M, Cantani E, Bonnet N, Gandjbakhch I. Videoassisted coronary artery bypass in patients with preexisting tracheostomy. Ann Thorac Surg. 1999;67:1153-4.

13. Erez E, Eldar S, Sharoni E, Abramov D, Sulkes A, Vidne BA. Coronary artery operation in patients after breast cancer therapy. Ann Thorac Surg. 1998;66:1312-7.

14. Safi HJ, Barnett MG, Turner W. Coronary artery bypass after substernal colon interposition for carcinoma of the esophagus. Cardiovasc Surg. 1994;2:415-7.

\section{ON THE MOVE?}

Don't miss a single issue of the journal! To ensure prompt service when you change your address, please photocopy and complete the form below.

Please send your change of address notification at least six weeks before your move to ensure continued service. We regret we cannot guarantee replacement of issues missed due to late notification.

\section{JOURNAL TITLE:}

Fill in the title of the journal here.

\section{OLD ADDRESS:}

Affix the address label from a recent issue of the journal here.

\section{NEW ADDRESS:}

Clearly print your new address here.

Name

Address

City/State/ZIP
COPY AND MAIL THIS FORM TO:

Mosby

Subscription Customer Service

6277 Sea Harbor Dr

Orlando, FL 32887
OR FAX TO:

407-363-9661

N/ Mosby
OR PHONE:

800-654-2452

Outside the U.S., call

407-345-4000 